\title{
Sport medicine, diabetes mellitus and ademolus classification of hypoglycaemia
}

\begin{abstract}
Sport has become a globally acceptable activity embraced by different cadre of the society. Competitive sporting activities whether at the amateur or professional level have become a means of livelihood among individuals or a means of interaction among nations. Also individuals engage in one form of sporting activity or the other in other to keep fit a behaviour that has medical backing. Some of the health benefits of sporting activities include improved cardiovascular health, the heart is a muscle and it needs to be exercised, lowers risk of heart disease, stroke, and diabetes, and helps manage weight. Reduce blood pressure, enhanced aerobic fitness, improved muscular strength and endurance, improved joint flexibility and range of motion and stress relief. On the other hand, physical inactivity is a modifiable risk factor for cardiovascular disease and a widening variety of other chronic diseases, including diabetes mellitus. Despite the health benefit of sporting activities, there are known deleterious effects like injury which a times are life or career threatening. Sporting activities in diabetic patients on insulin is known to result in hypoglycaemia. This review gives an insight on grading the severity of hypoglycaemia associated with sporting activities in people living with diabetes mellitus using Ademolus Classification of Hypoglycaemia (ACH).
\end{abstract}

Volume 7 Issue I - 2019

\author{
Adegbenga B Ademolu \\ Medicine Department, Lagos State University Teaching Hospital \\ Ikeja, Nigeria
}

\author{
Correspondence: Adegbenga B. Ademolu, Medicine \\ Department, Lagos State University Teaching Hospital \\ Ikeja, I-5, Oba Akinjobi way Ikeja GRA Lagos, Nigeria, Tel \\ +2348033575940, Email ademoluab@yahoo.com
}

Received: December 27, 2018 | Published: January 23, 2019

Keywords: sport medicine, diabetes mellitus, ademolus, hypoglycaemia, obesity, hypertension, cancer

Abbreviations: $\mathrm{ACH}$, ademolus classification of hypoglycaemia; cAMP, cyclic adenosine monophosphate; PKA, protein kinase $\mathrm{A}$

\section{Introduction}

Sport has become a globally acceptable activity embraced by different cadre of the society. Competitive sporting activities whether at the amateur or professional level have become a means of livelihood among individuals or a means of interaction among nations. Also individuals engage in one form of sporting activity or the other in other to keep fit a behaviour that has medical backing. Some of the health benefits of sporting activities include improved cardiovascular health, the heart is a muscle and it needs to be exercised, lowers risk of heart disease, stroke, and diabetes, helps manage weight. Reduce blood pressure, enhanced aerobic fitness, improved muscular strength and endurance, improved joint flexibility and range of motion and stress relief.

On the other hand, physical inactivity is a modifiable risk factor for cardiovascular disease and a widening variety of other chronic diseases, including diabetes mellitus, cancer (colon and breast), obesity, hypertension, bone and joint diseases (osteoporosis and osteoarthritis), and depression. ${ }^{1-14}$ There has been a dramatic increase in the amount of time spent performing deskbound, work-related activities in the United States. ${ }^{15,16}$ Deskbound activities promote little to no physical activity due to the predominance of seated or reclined postures. ${ }^{15-17}$ This lack of physical activity has contributed to the continual increase in obesity rates, ${ }^{15}$ the risk for developing diabetes, ${ }^{18,19}$ cardiovascular disease, and increased mortality rates. ${ }^{19,20}$

Despite the health benefit of sporting activities, there are known deleterious effects like injury which a times are life or career threatening. Sporting activities in diabetic patients on insulin is known to result in hypoglycaemia. This review gives an insight on grading the severity of hypoglycaemia associated with sporting activities in people living with diabetes mellitus using Ademolus Classification of Hypoglycaemia $(\mathrm{ACH})$ see Figure $1 .^{21}$

\section{Ademolus classification of hypoglycaemia (ACH)}

Figure 1 shows ACH which is a product of my over 15 years of rigorous work as a medical practitioner in both private and public health sector managing hypoglycaemic episodes amongst others in my patients. Grade 1 has predominantly adrenergic features, Grade 2 has adrenergic features with neuroglycopenic feature overlap, and Grade 3 has predominantly neuroglycopenic features that are majorly reversible while grade 4 has predominantly neuroglycopenic features with majorly irreversible brain damage.

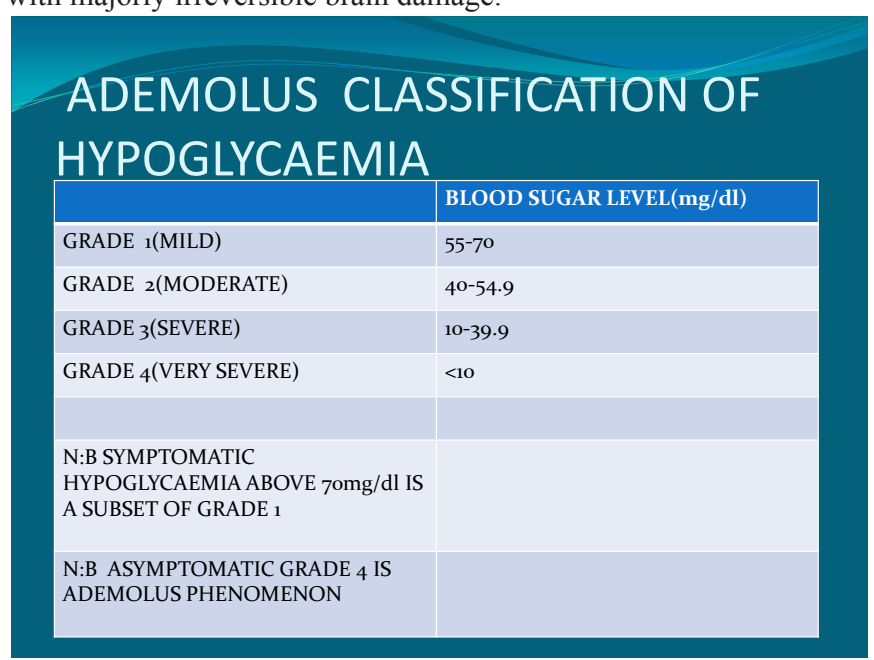

Figure I

Intermittent sports (e.g., team sports) are diverse in their rules and regulations but similar in the pattern of play; that is, intermittent high-intensity movements and the execution of sport-specific skills over a prolonged period of time $(\sim 1-2 \mathrm{~h}) .{ }^{22}$ Performance during 
intermittent sports is dependent upon a combination of anaerobic and aerobic energy systems, both of which rely on muscle glycogen and/ or blood glucose as an important substrate for energy production. This gives the possibility of muscle glycogen depletion and or blood glucose consumption to hypoglycaemic levels or range during sporting activities whether training or competition. The liver is the principal organ responsible for maintaining plasma glucose levels during times of increased demand, such as during exercise. When blood glucose levels start to fall, counter-regulatory hormones such as glucagon elevate cyclic adenosine monophosphate (cAMP) and protein kinase A (PKA) activity, which stimulate glycogen breakdown and gluconeogenesis (de novo production of glucose), increasing hepatic glucose output. In contrast, insulin suppresses hepatic glucose production and promotes glucose storage as glycogen in hepatocytes. The ratio of insulin to glucagon levels dictates whether the liver will store glucose (high insulin) or produce glucose for use by the rest of the body (low insulin) at such times. Hepatocytes express an insulin-insensitive glucose transporter isoform termed GLUT2 that is always present at the cell surface, enabling glucose uptake during hyperglycemia and glucose release into the bloodstream during episodes of hypoglycemia. Exercise is an important component of the management of type 2 diabetes. Plasma glucose concentrations decrease after exercise, as there is a significant improvement in insulin sensitivity. Insulin promotes glucose uptake in skeletal muscle by stimulating the translocation of specialized vesicles containing the facilitative glucose transporter isoform GLUT4 from the perinuclear region to the cell surface. Exercise-induced hypoglycemia in patients with type 2 diabetes is primarily due to reduced physiological need for insulin given the increased insulin sensitivity coupled with either exogenous insulin or the use of insulin secretegogues. With the cut off of hypoglycaemia put at $70 \mathrm{mg} / \mathrm{dl}$ by the American diabetic association and Ademolus Classification of Hypoglycaemia in diabetics this level could be reached and further the blood glucose level could dip as sporting activities continues without replacement.

At the onset of the hypoglycaemic episodes which is usually marked by adrenergic symptoms, the sportman/sportwoman may not easily take cognisance of this as attention then may be or will be at the field of play or on the game, however at a particular critical level of hypoglycaemias which may be individual specific, the sportman may develop neuroglycopaenic features, loose concentration (as seen in tennis,), miscalculate ,become confused (may occur in marathon runners)and if not checked may loose consciousness in the field of play. This is why every sportmen that loose consciousness or fall unchallenged in the field of play should be given the privilege of having a blood sugar check at that critical point and then the grade of hypoglycaemia the sportman or woman have should be characterised at that point using $\mathrm{ACH}$.

The hypoglycaemia may be the sole reason for the unchallenged collapse or loss of consciousness or may be part of a constellation of pathophysiological processes culminating in the loss of consciousness. Using ACH at this point will help to know the severity of hypoglycaemia that is associated with the concerned individual"s loss of consciousness and it will not be out of place to give such individual (sportsman/sportswoman) the benefit of regular check of blood sugar during future sporting activities relatively to others for instance if such individual is a footballer, checking his/her blood sugar as a routine at half time in a future game will not be out of place but will be a form of primary prevention of another episode of hypoglycaemia.
Since hypoglycaemia can occur at different level of severity, a series of documented hypoglycaemic episodes grade(s) in the same individual diabetic sportsman/sportswoman obtainable using ACH can help a lot to adjust as appropriate the insulin regimen the sportsperson will be on whether as insulin pump, basal insulin or glargine or short acting insulin. Hence $\mathrm{ACH}$ can help a lot in individualized therapy in diabetes mellitus management in sportsmen.

Not only this,in a known diabetic engaged in active sporting activities who is prone to hypoglycaemia for instance a type 1 diabetic patient on insulin, using $\mathrm{ACH}$ will help to objectively warn on possibility of imminent danger if during sporting activities break/rest time ,the diabetic spontaneously check his/her blood sugar level and found it to be grade 1 hypoglycaemia, in such scenario, the onus is on the sportsperson to quickly take glucose drink or for the coach to offer it. This is applicable to diabetics on insulin participating in football, basketball, boxing, wrestling, long jump, triple jump, and track and field events that involve multiple "heat" sessions in a single day, the blood sugar can be checked after each session, if the individual still have other sessions ahead that same day.

Similarly some sporting activities goes into extra time by virtue of circumstances of the game, these extra time is a period when hypoglycaemic tendencies are higher or more likely as usually there is no meal in between full time and extra time as seen in football games, however in between the blood sugar of the diabetic on insulin involved in such game could be checked as it cannot be the same as it was at the beginning of the game. This proactive act will help to pick asymptomatic hypoglycaemia usually seen in grade 1 hypoglycaemia using $\mathrm{ACH}$ in the sportsperson concerned and it can be corrected quickly with a glucose drink before progression to other grades of hypoglycaemia which is associated with poorer prognosis since prognosis get worse as blood glucose level decline from grade 1, to grade 2 to grade 3 and grade 4 using $\mathrm{ACH}$. This is one of the uses of $\mathrm{ACH}$ as a prognostic factor in people living with diabetes mellitus involved in sport.

Also neuroglycopaenic hypoglycaemic features in a diabetic involved in motor racing may result in a crash if not anticipated and checked.

\section{Sport medicine non-diabetics and ademolus classification of hypoglycaemia}

Hypoglycaemia does not spare the non diabetic sportsmen/ sportswomen; ACH can be applied to these too. Long distance runners and marathon runners especially are at risk of hypoglycaemia from continuous and prolonged blood glucose consumption, hence 1 am advocating that checking blood sugar level should be a routine immediately after each race in all long distance athletes runners in order to screen for and correct (if detected) hypoglycaemia of any grade using $\mathrm{ACH}$.

\section{Conclusion}

Ademolus Classification of Hypoglycaemia ACH is invaluable in sport medicine as it is relevant in managing hypoglycaemia developing during training or competition in athletes whether they are diabetic or not.

\section{Acknowledgment}

None. 


\section{Conflicts of interest}

The author declares there is no conflict of interest.

\section{References}

1. Bouchard C, Shephard RJ. Physical activity fitness and health: the model and key concepts. In: Bouchard C, Shephard RJ, Stephens T, editors. Physical activity fitness and health: International proceedings and consensus statement. Champaign (IL): Human Kinetics; 1994. p. 77-88.

2. Blair SN, Brodney S. Effects of physical inactivity and obesity on morbidity and mortality: current evidence and research issues. Med Sci Sports Exerc. 1999;31(11 Suppl):S646-S662.

3. American College of Sports Medicine. Position stand: Exercise and physical activity for older adults. Med Sci Sports Exerc. 1998;30:9921008.

4. McAuley E. Physical activity and psychosocial outcomes. In: Bouchard C, Shephard RJ, Stephens T, editors. Physical activity, fitness and health: the consensus knowledge. Champaign (IL): Human Kinetics; 1994. p. 551-568.

5. Taylor RS, Brown A, Ebrahim S, et al. Exercise-based rehabilitation for patients with coronary heart disease: systematic review and metaanalysis of randomized controlled trials. Am J Med. 2004;116(10):682692.

6. Blair SN, Cheng Y, Holder JS. Is physical activity or physical fitness more important in defining health benefits? Med Sci Sports Exerc. 2001;33(6 Suppl):S379-S399.

7. Blair SN, Kohl HW, Paffenbarger RS, et al. Physical fitness and allcause mortality. A prospective study of healthy men and women. JAMA. 1989;262(17):2395-2401.

8. Paffenbarger RS, Hyde RT, Hsieh CC, et al. Physical activity, other lifestyle patterns, cardiovascular disease and longevity. Acta Med Scand Suppl. 1986;711:85-91.

9. Warburton DE, Gledhill N, Quinney A. Musculoskeletal fitness and health. Can J Appl Physiol 2001;26(2):217-237.

10. Warburton DE, Gledhill N, Quinney A. The effects of changes in musculoskeletal fitness on health. Can J Appl Physiol 2001;26(2):161216.
11. U.S. Department of Health and Human Services. Healthy people 2000: national health promotion and disease prevention objectives. In. Washington: US Department of Health and Human Services; 1991.

12. Puett DW, Griffin MR. Published trials of nonmedicinal and noninvasive therapies for hip and knee osteoarthritis. Ann Intern Med. 1994;121(2):133-140.

13. Shephard RJ. Absolute versus relative intensity of physical activity in a dose- response context. [discussion S419-20]. Med Sci Sports Exerc. 2001;33(6 Suppl):S400-S418.

14. Lee IM, Skerrett PJ. Physical activity and all-cause mortality: What is the dose- response relation? [discussion S493-4]. Med Sci Sports Exerc. 2001;33(6):S459-S471.

15. Church TS, Thomas DM, Tudor-Locke C, et al. Trends over 5 decades in U.S. occupation-related physical activity and their associations with obesity. PloS One. 2011;6(5):e19657.

16. Parry S, Straker L. The contribution of office work to sedentary behaviour associated risk. BMC Public Health. 2013;13(1):296.

17. Barnes J, Behrens TK, Benden ME, et al. Letter to the editor: standardized use of the terms "sedentary" and "sedentary behaviours". Appl Physiol Nutr Metab. 2012;37(3):540-542.

18. Hamilton MT, Hamilton DG, Zderic TW. Role of low energy expenditure and sitting in obesity, metabolic syndrome, type 2 diabetes, and cardiovascular disease. Diabetes. 2007;56(11):2655-2667.

19. Wilmot E, Edwardson C, Achana F, et al. Sedentary time in adults and the assciation with diabetes, cardiovascular disease and death: systematic review and meta-analysis. Diabetologia. 2012;55(11):28952905.

20. John RH, Jeffrey DE, Dustin DD, et al. Effects of Task Difficulty on Kinematics and Task Performance during Walking Workstation Use. Translational Journal of the ACSM. 2018;3(11):74-84.

21. Ademolu AB. Role of Ademolus Classification of Hypoglycemia in Blood Glu-cose and Diabetes Mellitus Management. Gastroenterol Liver Clin Med. 2017;1:1 003.

22. Baker LB, Rollo I, Stein KW, et al. Acute Effects of Carbohydrate Supplementation on Intermittent Sports Performance. Nutrients. 2015;7(7):5733-5763. 